For personal use only. Not to be reproduced without permission of the publisher (editorial@gabi-journal.net).

\title{
Ongoing initiatives to improve prescribing efficiency in China; statins as a case history
}

\author{
Wenjie Zeng' ',Bsc, PhD; Houmei Xi', B Eng; Brian Godman ${ }^{2,3,4}$, BSc, PhD; Alexander E Finlayson ${ }^{5}, M D, M R C P$; \\ Rickard EMalmstrom ${ }^{6}, M D, P h D$
}

\begin{abstract}
Introduction: Pharmaceutical expenditure rose by $16 \%$ per annum in China during the past decade, and now represents $46 \%$ of total healthcare expenditure. Initiatives to moderate growth include pricing regulations for pharmaceuticals and encouraging International Nonproprietary Name (INN) prescribing. However, there is limited monitoring of physician prescribing and current incentives encourage hospitals and physicians to profit from drug procurement.

Objective: Assess changes in statin utilization and expenditure as additional generics are launched. Subsequently, compare results in China with findings among European countries to provide future guidance.

Methods: Observational retrospective study of statin utilization and procurement expenditure from 2004 to 2013 in two large teaching hospital groups.

Results: Statin utilization rose 32-fold in one hospital group and 54-fold in the other. Expenditure also increased but to a lesser extent, i.e. from just over Renminbi 'yuan' (CNY) 0.65 million in 2004 to CNY 15.3 million in 2013 in one hospital group and from CNY 0.49 to CNY 19.3 million in the other. Atorvastatin (originator) was the most utilized statin. Utilization of each generic statin was typically low, e.g. 10\% in 2013 in one hospital group. Procurement prices fell over time, greatest for generic simvastatin (-74\% to -91\%) mirroring data from European countries. However, no increase in their prescribing was observed. In fact, a significant decrease in generic prescribing was seen in one hospital group between 2004 and 2013.

Conclusion: There are considerable opportunities to improve prescribing efficiency in China based on European experience. However, current incentives encouraging hospitals and physicians to profit from drug procurement need to be addressed.
\end{abstract}

Keywords: China, drug utilization study, generics, health policies, pharmaceuticals, prices, statins

\section{Introduction}

There is increasing scrutiny of the growth in pharmaceutical expenditures in many countries in recent years. Growth rates averaged $50 \%$ in real terms during the past decade [1-3] has resulted in multiple reforms across countries. This growth has been driven by well-known factors including ageing populations and new premium priced drugs [1, 2, 4-6]. Initiatives for new medicines include models to better manage their entry to optimize the use of available resources [6-8]. Initiatives for established medicines include measures to enhance the utilization of low cost generics rather than originators and single sourced (patented) products in a single or related class where all products are seen as essentially similar [2, 6, 9-11]. Examples include the proton pump inhibitors (PPIs), statins and renin-angiotensin system inhibiting drugs [2, 6, 12-20], with the latter including both angiotensin converting enzyme inhibitors (ACEIs) and the angiotensin receptor blockers (ARBs).

Savings can be substantial for the medicines in these classes that are essentially therapeutically equivalent when the medicines are given in appropriate doses, because the prices of generics are as low as $2 \%$ to $10 \%$ of pre-patent loss prices in some countries [2, 12, 18, 21-23]. Multifaceted demand-side measures enacted to achieve these savings include high International Nonproprietary Name (INN) prescribing, formularies, prescribing guidance, continuous medical education, quality circles, strengthening of drug and therapeutic committees (DTCs), prescribing targets, financial incentives and prescribing restrictions $[2,12,13,18,19,21$, 24-26]. Considerable savings can also be achieved in low- and middle-income countries from switching from use of originators to use of the lowest-priced equivalent generic drugs [27-29].

China has also seen considerable increases in pharmaceutical expenditure in recent years, which has been growing at over $16 \%$ per annum during the past decade [29-32]. This has continued in the current decade [33]. This growth has been principally driven by increasing insurance coverage [34]. The Chinese Government has introduced three different types of health insurance in recent years each targeting different populations, with basic coverage reaching over $90 \%$ of the population in 2011 [33, 35-37] and 95\% in 2013 [33]. The ultimate goal is universal coverage by 2020 [35-40]. As a result of increased coverage, total healthcare expenditure increased from 3.5\% to 5\% of gross domestic product between 1995 and 2010, equating to a 10 -fold increase in per capita spending from US\$21 to US $\$ 220$ [35]. Expenditure has increased more rapidly in recent years reaching US $\$ 350$ per capita in 2011 [33]. In 2010, pharmaceutical revenues for Chinese public hospitals was CNY 405.39 billion (approximately US\$62.4 billion), 46\% of total healthcare expenditure [29, 41], with out-of-pocket payments accounting for $36 \%$ of total healthcare expenditure [35]. Pharmaceuticals accounted for $40 \%$ to $50 \%$ of hospital revenues in the past decade [33].

As a result, China has introduced a number of measures in recent years to help moderate this growth. These measures have principally been aimed at trying to control pharmaceutical expenditure in hospitals, because more than $80 \%$ of total pharmaceutical consumption in China is currently occurring in hospitals [29,35, 37, 42].

Author for correspondence: Brian Godman, BSc, PhD, Department of Laboratory Medicine, Division of Clinical Pharmacology, Karolinska Institutet, Karolinska University Hospital Huddinge, SE-14186 Stockholm, Sweden

Submitted: 8 May 2014; Revised: 19 August 2014; Accepted: 19 August 2014; Published online first: 1 September 2014 
For state-priced products, the National Development and Reform Commission (NDRC) sets maximum retail prices (price cap) including mark-ups; for province- or municipality-priced products, the price management department determines the retail prices. For other products, retail prices are determined by the manufacturers [29, 35, 42, 43]. For instance, the NDRC has implemented 28 price adjustments between 1997 and 2011 to address high prices for common or expensive medicines, such as cardiovascular drugs or anticancer drugs [29, 44]. There were also eight price cuts for antibiotics between 2000 and 2005 [31]. Medicines in hospitals are subject to tenders in each province and municipality with each hospital pharmacy deciding on its own procurement list. This has resulted in cardiovascular drug prices changing four times between 2006 and 2011 in Chongqing Urban District alone [29]. Published studies have suggested these bidding processes reduced the prices of essential medicines by 16.9\% between 2009 and 2011 [35]. However, there are no formal pricing policies for generics in China unlike the policies introduced across Europe, which have resulted in low prices $[2,4,10,12,16,18,21,45]$. This lack of policies is at least partially responsible for the fact that there are more than 5,000 pharmaceutical manufacturers in China producing mainly generics $[29,33,42]$. It is expected, but not yet proven, that greater transparency in pharmaceutical pricing may lead to further price reductions [35].

Demand-side measures undertaken in China include the development of an essential medicine list, clinical guidance and guidelines [30, 33, 35, 46, 47]. However, currently there are limited measures being taken by public insurers to monitor the quality of prescribing [48, 49]. There were reforms introduced in 2007 the 'Prescription Management Ordinance' - specifying that prescriptions should be written by generic (INN) name. However, to date there has been limited enforcement [29, 43]. As a consequence, physicians tend to write prescriptions with the generic (INN) name and simultaneously indicate the brand or manufacturer's name; alternatively, they simply choose medicines listed in hospitals' information technology (IT) systems with the corresponding brand name or manufacturer [29, 43]. This situation is not helped by having similar patient co-payments for an originator or a generic drug. In addition, in the current system, hospitals typically use the profits from medicine procurement for their sustainability [33, 47, 49].

Pharmaceutical expenditure in hospitals accounted for $41.5 \%$ to $46 \%$ of hospitals' total income between 2006 and 2010 [29, 33, $41,43,46,48]$. This is because the financial support from the Chinese Government to public hospitals declined steadily from approximately $40 \%$ to $60 \%$ of hospital revenues in 1980s, to $17 \%$ in the late 1990 s and to $8.2 \%$ by 2003 [29, 31]. Consequently, hospitals use the revenue from a permitted 15\% mark-up in drug procurement for their sustainability [29, 31, 33, 35, 43]. Even after attempts to reduce procurement prices, the actual mark-up of medicines in hospitals in 2005 averaged approximately $42 \%$ [43]. There are also inducements for physicians to overprescribe drugs as well as prescribe drugs that produce the greatest profit for them and the hospital [29, 31, 33, 49], e.g. bonuses physicians receive directly from the manufacturers for prescribing their products. According to a study of 12 hospitals in Beijing from 1996 to 2005, expenditure on antibacterial medicines increased due to expensive antibiotics being prescribed rather than cheaper alternatives [31]. This situation is exacerbated by the low salaries currently paid to physicians in China; with many physicians earning CNY 5,000 (US\$780) a month or less [50, 51]. This has resulted in considerable irrational prescribing despite the introduction of measures such as essential medicine lists to decrease this [29, 31, 33, 42, 43]. An example of irrational prescribing is the continued inappropriate use of injectable drugs including injectable traditional Chinese medicines as well as considerable overprescribing of antibiotics including, as mentioned, the use of expensive versus less expensive antibiotic alternatives [31, 32, 49, 52, 53].

A number of issues and findings have recently been identified, see Box 1, for the use of cardiovascular medicines in the Chongqing Region of China [29].

For a number of reasons, see Box $2[6,12,15,17,18,20,21,25$, $40,52]$, the authors felt a study looking specifically at all the statins procured in China and for a longer time period was justified.

Consequently, the principal objective of this paper was to assess changes in the utilization and expenditure on statins in China when generic statins are included in procurement lists. The authors hoped to use the data generated to suggest potential future reforms that China could consider to enhance prescribing efficiency as China strives for universal health access such as that which exists in Europe.

\section{Methods}

Typically for these types of drug utilization analyses, data are obtained from health authority, health insurance or pharmacy databases [12, 14, 16, 18, 19, 22, 23, 25, 54]. However in China, drug utilization studies are often performed with data from hospitals as they incorporate both inpatient and outpatient data $[29,55]$. In addition, as mentioned, these data account for $80 \%$ of total drugs currently dispensed in China [29, 40]. This is related to the convenience of hospital dispensing which is

\section{Box 1: Findings for cardiovascular medicines in the Chongqing} Region in China from 2006 to 2011

- The market share of generics among 12 leading cardiovascular (CV) drugs decreasing from 50\% in the first half of 2006 to $34 \%$ by the end of 2011 , with the market share of originators increasing to 66\% by the end of 2011 (based on defined daily doses).

- The market share of originators appreciably increased between 2006 and 2008; however, narrower fluctuations after this.

- Generic versions were available for all 12 CV drugs studied from 2006, with the price of originators averaging 63\% greater than generics prices in 2011. These included three of the statins.

- Overall, the prices of generics for the $12 \mathrm{CV}$ drugs studied varied from 0.34 to 0.98 of the originator in 2011 , i.e. $2 \%$ to $66 \%$ price difference.

- There was potential for considerable savings with greater use of generics in this region if this could be engineered through additional demand-side measures. 
Box 2: Rationale for studying statin utilization and expenditure in China

- Ischaemic heart disease and cerebrovascular disease are among the leading causes of death in China.

- Lack of appreciable therapeutic differences between the various statins or between originator and generic statins.

- Published studies have shown that patients can be successfully switched between statins without compromising care.

- The recent expansion of the utilization of statins with greater use in non-CV disease populations, e.g. patients with diabetes in addition to those with coronary vascular disease.

- The fact that some but not all previous studies in China have shown that appreciable price reductions are possible for generics.

- The considerable variation in demand-side measures used in Western European countries to encourage the preferential prescribing of low cost generic statins and the appreciable differences in the eventual utilization of generic and single-sourced statins produced by these measures.

- The paucity of data on the economic effects of various measures used in China to encourage statin use.

- Between 2006 and 2011, some generic statins were included in hospital lists in China. As a result, providing an opportunity to further evaluate generic penetration rates and savings compared to the situation summarized in Box 1.

based on physician recommendations. Such data also eliminates the possibility of non-standardized community-based prescriptions and there is greater assurance of pharmaceutical quality in hospitals [43]. Consequently, hospital procurement data are currently an optimal source of drug utilization data in China. Accurate data on hospital tendering and procurement is especially important for this type of analysis [43, 47, 49]. These data are not always available from some commercial sources, which provide only maximum retail price data [30]. Hospital procurement prices are also not always captured in health insurance data. In addition, hospitals may dispense medicines that are not currently reimbursed. As a result, health insurance data are not the optimal data source for comprehensive drug utilization studies in China.

Chongqing is a municipality directly under China's central government, with a total population of 28.8 million people (2010 census). In the urban district in Chongqing City, the main public general hospitals include three hospitals affiliated with the Third Military Medical University (TMMU), two hospitals affiliated with Chongqing Medical University (CMU), and 10 municipal hospitals. Each hospital can dispense generic drugs from different manufacturers, but each has the same originator equivalents because there are only a limited number of originator manufacturers [29].

We chose two teaching hospital groups in the Chongqing District to conduct our study (CMU and TMMU). These two hospital groups we felt to be both representative of the entire Chongqing District and also able to provide comprehensive datasets on both utilization and expenditures. In view of the complexity of the procurement process only the largest hospitals, e.g. TMMU, tend to have a comprehensive range of products available for prescribing, which may influence procured prices and utilization patterns. The dataset was obtained from the company publishing journals, one of which is called China Pharmacy. The company is located in Chongqing and collects detailed information from large hospitals in southwest China through cooperation with public hospitals. The data contains all individual drug information including product names, purchase dates, dosage forms, specifications, manufacturers, unit prices and volumes. This is an authoritative source for drug utilization statistics in China which is regularly audited. We have used a similar approach in a previous study [29].

An observational, uncontrolled, retrospective study of prescriptions between 2004 and 2013 was performed [56]. The time period includes the period of the previous study, see Box 1 . This methodology was chosen because multiple supply- and demandside measures had been introduced during this period in China making it difficult to perform an interrupted time series analysis. In addition, multiple generic statins are available in China, see Table 1, [57] and there were multiple changes to the procurement of statins over this period, see Table 2. Both chi-square and the Fischer exact tests were undertaken to assess potentially significant changes in the prescribing of generics versus originators.

\begin{tabular}{|l|l|}
\multicolumn{2}{|c|}{$\begin{array}{l}\text { Table } \\
\text { generic statin preparations in China in January 2014 [57] }\end{array}$} \\
\hline Statin & Registered number of approvals \\
\hline Simvastatin & 156 \\
\hline Rosuvastatin & 13 \\
\hline Pravastatin & 13 \\
\hline Atorvastatin & 9 \\
\hline Pitavastatin & 6 \\
\hline Fluvstatin & 5 \\
\hline Registered approvals for production of raw material drug are excluded. \\
\hline
\end{tabular}

Table 2: Procurement availability of statins from 2004 to 2013

\begin{tabular}{|l|l|l|l|l|}
\hline \multirow{2}{*}{ Statins } & \multicolumn{2}{|l|}{ TMMU hospital group } & \multicolumn{2}{|c|}{ CMU hospital group } \\
\cline { 2 - 5 } & Originator & Generic & Originator & Generic \\
\hline Simvastatin & $\begin{array}{l}2004 \\
\text { onwards }\end{array}$ & $\begin{array}{l}\text { Available } \\
\text { from 2004 }\end{array}$ & $\begin{array}{l}2004 \\
\text { onwards }\end{array}$ & $\begin{array}{l}\text { Available } \\
\text { from 2004 }\end{array}$ \\
\hline Pravastatin & $\begin{array}{l}2004 \\
\text { onwards }\end{array}$ & $\begin{array}{l}\text { 2009 June } \\
\text { onwards }\end{array}$ & $\begin{array}{l}2004 \\
\text { onwards }\end{array}$ & $\begin{array}{l}\text { Not } \\
\text { available }\end{array}$ \\
\hline Fluvastatin & $\begin{array}{l}2004 \\
\text { onwards }\end{array}$ & $\begin{array}{l}\text { Not } \\
\text { available }\end{array}$ & $\begin{array}{l}\text { 2004 } \\
\text { onwards }\end{array}$ & $\begin{array}{l}\text { Not } \\
\text { available }\end{array}$ \\
\hline Atorvastatin & $\begin{array}{l}2004 \\
\text { onwards }\end{array}$ & $\begin{array}{l}\text { Available } \\
\text { from 2004 }\end{array}$ & $\begin{array}{l}\text { 2005 June } \\
\text { onwards }\end{array}$ & $\begin{array}{l}\text { Available } \\
\text { from 2004 }\end{array}$ \\
\hline Pitavastatin & $\begin{array}{l}2010 \text { July } \\
\text { onwards }\end{array}$ & $\begin{array}{l}\text { 2012 April } \\
\text { onwards }\end{array}$ & $\begin{array}{l}\text { Not } \\
\text { available }\end{array}$ & $\begin{array}{l}\text { Not } \\
\text { available }\end{array}$ \\
\hline Rosuvastatin & $\begin{array}{l}\text { 2008 } \\
\text { February } \\
\text { onwards }\end{array}$ & $\begin{array}{l}\text { 2009 July } \\
\text { onwards }\end{array}$ & $\begin{array}{l}\text { 2010 } \\
\text { December } \\
\text { onwards }\end{array}$ & $\begin{array}{l}\text { Not } \\
\text { available }\end{array}$ \\
\hline
\end{tabular}

Generics may have been available in China during previous years; however, just not included in the hospital procurement process in view of the different choices available. CMU: Chongqing Medical University; TMMU: Third Military Medical University. 
The Chinese currency, the Renminbi 'yuan' (CNY), was used to determine expenditure and expenditure/DDD for statins over time. There was no allowance for inflation as we wanted to compute actual changes over time as a result of the tendering process. This is because most health authorities typically decrease prices when budgets are being exceeded [58, 59] making adjustments based on factors, such as retail price indexes or purchasing price parity difficult to justify when reviewing pharmaceutical prices. This is in line with previous studies [12, $13,18,19,22,23,25,54,60]$. We also did not convert CNY data to either US\$ or Euros during the course of the study as we did not want the pricing information influenced by currency fluctuations; especially during the recent financial crises in Europe and the US. Originator statins are those products currently or previously possessing intellectual property (patent), which either come from multinational companies or are manufactured by joint ventures in China founded by multinational pharmaceutical companies. Generic drugs are domestic products produced by Chinese enterprises with local investment, including stateowned and private enterprises. There is strong competition between a large number of manufacturers, see Table 1 .

Six statins were available between 2004 and 2013 in the TMMU hospital (ATC C10AA01, C10AA03, C10AA04, C10AA05, C10AA07, C10AA08 [61], and five statins in the CMU hospital, see Table 2. Utilization was measured in terms of Defined Daily Dose (DDDs); defined as the average maintenance dose of a drug when used in its major indication in adults', with this measure recognized as the international standard to assess utilization patterns within and between countries [62]. 2011 DDDs were defined based on international guidance [62-64].

\section{Results \\ Utilization}

There was an appreciable increase in the prescribing of statins during the study period, increasing 32 - fold from just over 67,000 DDDs in 2004 to 2.17 million in 2013 across all products for the TMMU hospitals, see Figure 1, and 54-fold from over 49,000 DDDs to 2.69 million for the CMU hospitals, see Figure 2.

The greatest increase in utilization was seen with atorvastain (originator and generic drug in the TMMU hospitals, and only originator in the CMU hospitals) and simvastatin, although the consumption of the later decreased in recent years, see Figures 1 and 2, Table 3. The utilization of both rosuvastatin and fluvastatin also increased steadily but to a lesser extent.

In January 2010, the originator manufacturer adjusted its price of simvastatin tablets $40 \mathrm{mg} \times 5$ 's from CNY 50.30 to CNY 26.70 in TMMU hospitals (slightly changed to CNY 26.61 in February 2011) and its utilization subsequently increased, see Table 3. In September 2011 (November 2011 in CMU hospitals), the manufacturer changed the specification to $40 \mathrm{mg} \times 7$ 's, and priced at CNY 36.81. Its utilization subsequently decreased in the TMMU hospitals and in 2013 in the CMU hospitals. Meanwhile, the utilization of atorvastatin and rosuvastatin increased, see Figures 1 and 2, Table 3 .

There was variable use of generic statins in the two hospitals. In the TMMU hospitals, there was a rapid increase in the use of generics. The utilization of generic atorvastatin peaked at

\section{Figure 1: Utilization of statins (DDDs) between 2004 and 2013 in the TMMU hospitals}

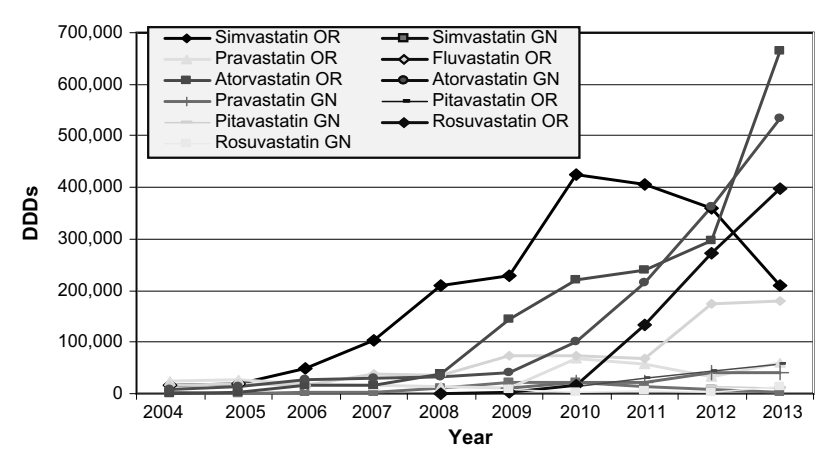

DDD: Defined Daily Dose; GN: generic; OR: originator; TMMU: Third Military Medical University.

\section{Figure 2: Utilization of statins (DDDs) between 2004 and 2013 in the CMU hospitals}

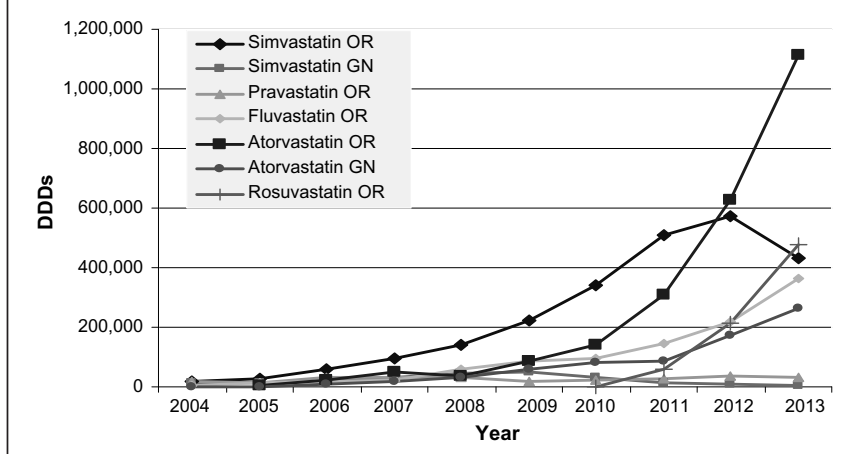

CMU: Chongqing Medical University; DDD: Defined Daily Dose; GN: generic; OR: originator.

$97 \%$ of total atrovastatin in 2004 before declining to $22 \%$ in 2009 , and subsequently increased to between $45 \%$ and $55 \%$ in recent years. A similar pattern was seen for generic pravastatin once it was procured, peaking at $50 \%$ of total pravastatin utilization in 2009 before falling to $24 \%$ in 2010 and subsequently increasing to between $41 \%$ and $57 \%$ in recent years, see Figure 1, Table 3. However, there was limited use of generic pitavastatin and rosuvastatin in recent years, see Table 3 . The variable use of generics among the statins led to their overall utilization increasing from $18 \%$ of total statins in 2004 to $28 \%$ in 2013 in the TMMU hospitals, see Table 3. However, the difference in the utilization of generic versus originator statins between 2004 and 2013 was not significant by chi-square test ( $p>0.05$ ) despite the increasing availability of generic statins, see Tables 2 and 3.

In the CMU hospitals, the greatest increase was for atorvastatin (3,936-fold), see Figure 2, Table 3. However, owing to decreasing utilization of generic atorvastatin as a percentage of total atorvastatin, there was decreasing use of generic statins from $9 \%$ to $10 \%$ of total statins in recent years, see Table 3 . In this hospital group, there was a significant difference in the utilization of generic versus originator statins between 2004 and 2013 ( $\mathrm{p}<0.01$ using the chi-square test). 


\begin{tabular}{|c|c|c|c|c|c|c|c|c|c|c|c|}
\hline TMMU hospitals & 2004 & 2005 & 2006 & 2007 & 2008 & 2009 & 2010 & 2011 & 2012 & 2013 & $\begin{array}{l}\text { Degree of } \\
\text { change }\end{array}$ \\
\hline Simvastatin (O) & 15,323 & 18,133 & 48,067 & 104,027 & 209,333 & 228,800 & 425,333 & 405,333 & 360,267 & 210,933 & \\
\hline Simvastatin $(\mathrm{G})$ & 2,453 & 560 & 1,792 & 1,848 & 9,576 & 22,008 & 20,627 & 14,933 & 7,840 & 2,240 & \\
\hline$\%$ Genenric & $13.8 \%$ & $3.0 \%$ & $3.6 \%$ & $1.7 \%$ & $4.4 \%$ & $8.8 \%$ & $4.6 \%$ & $3.6 \%$ & $2.1 \%$ & $1.1 \%$ & \\
\hline Pravastatin $(\mathrm{O})$ & 23,969 & 27,986 & 19,291 & 15,395 & 14,833 & 11,433 & 67,200 & 56,933 & 31,873 & 58,800 & \\
\hline Pravastatin (G) & & & & & & 11,267 & 21,467 & 22,667 & 41,327 & 39,980 & \\
\hline Pravastatin (Total) & 23,969 & 27,986 & 19,291 & 15,395 & 14,833 & 22,700 & 88,667 & 79,600 & 73,200 & 98,780 & 4.1 \\
\hline Atorvastatin (G) & 9,282 & 13,580 & 26,880 & 29,400 & 31,353 & 41,160 & 102,057 & 215,320 & 361,491 & 532,560 & \\
\hline Atorvastatin (Total) & 9,562 & 15,715 & 42,511 & 47,040 & 68,726 & 186,760 & 322,137 & 454,440 & 657,465 & $1,197,770$ & 125.3 \\
\hline$\%$ Genenric & $97.1 \%$ & $86.4 \%$ & $63.2 \%$ & $62.5 \%$ & $45.6 \%$ & $22.0 \%$ & $31.7 \%$ & $47.4 \%$ & $55.0 \%$ & $44.5 \%$ & \\
\hline Pitavastatin (O) & & & & & & & 13,790 & 30,030 & 42,350 & 57,330 & \\
\hline Pitavastatin (G) & & & & & & & & & 14,000 & 10,360 & \\
\hline Pitavastatin (Total) & & & & & & & 13,790 & 30,030 & 56,350 & 67,690 & \\
\hline$\%$ Genenric & & & & & & & & & $24.8 \%$ & $15.3 \%$ & \\
\hline Rosuvastatin (O) & & & & & 1,134 & 1,400 & 15,400 & 133,497 & 273,413 & 398,160 & \\
\hline Rosuvastatin (G) & & & & & & 7,896 & 1,729 & 5,600 & 2,800 & 12,600 & \\
\hline Total Statins & 67,201 & 82,018 & 129,006 & 207,137 & 337,949 & 544,231 & 962,116 & $1,191,660$ & $1,606,614$ & $2,167,373$ & 32.3 \\
\hline$\%$ Genenric & $17.5 \%$ & $17.2 \%$ & $22.2 \%$ & $15.1 \%$ & $12.1 \%$ & $15.1 \%$ & $15.2 \%$ & $21.7 \%$ & $26.6 \%$ & $27.6 \%$ & \\
\hline CMU hospitals & 2004 & 2005 & 2006 & 2007 & 2008 & 2009 & 2010 & 2011 & 2012 & 2013 & $\begin{array}{l}\text { Degree of } \\
\text { change }\end{array}$ \\
\hline Simvastatin (O) & 16,053 & 27,733 & 57,700 & 95,020 & 143,060 & 223,803 & 338,800 & 505,067 & 552,533 & 431,200 & \\
\hline Simvastatin (G) & 11,627 & 12,333 & 19,036 & 30,053 & 46,422 & 50,003 & 33,150 & 11,867 & 7,667 & 5,950 & \\
\hline Simvastatin (Total) & 27,680 & 40,066 & 76,736 & 125,073 & 189,482 & 273,807 & 371,950 & 516,933 & 560,200 & 437,150 & 15.8 \\
\hline$\%$ Genenric & $42.0 \%$ & $30.8 \%$ & $24.8 \%$ & $24.0 \%$ & $24.5 \%$ & $18.3 \%$ & $8.9 \%$ & $2.3 \%$ & $1.4 \%$ & $1.4 \%$ & \\
\hline Pravastatin $(\mathrm{O})$ & 17,096 & 14,026 & 33,250 & 33,500 & 31,477 & 18,877 & 24,383 & 27,067 & 37,800 & 30,800 & 1.8 \\
\hline Fluvastatin (O) & 4,247 & 14,933 & 16,427 & 23,893 & 56,929 & 86,613 & 96,740 & 146,347 & 216,907 & 363,440 & 85.6 \\
\hline Atorvastatin (O) & & 3,080 & 21,077 & 49,980 & 35,658 & 84,140 & 140,910 & 308,140 & 626,080 & $1,113,910$ & \\
\hline Atorvastatin $(G)$ & 350 & 1,820 & 7,070 & 17,710 & 33,180 & 59,640 & 82,320 & 88,200 & 172,200 & 263,760 & \\
\hline Atorvastatin (Total) & 350 & 4,900 & 28,147 & 67,690 & 68,838 & 143,780 & 223,230 & 396,340 & 798,280 & $1,377,670$ & $3,936.20$ \\
\hline$\%$ Genenric & $100 \%$ & $37.1 \%$ & $25.1 \%$ & $26.2 \%$ & $48.2 \%$ & $41.5 \%$ & $36.9 \%$ & $22.3 \%$ & $21.6 \%$ & $19.1 \%$ & \\
\hline Rosuvastatin (O) & & & & & & & 350 & 57,890 & 212,940 & 478,800 & \\
\hline
\end{tabular}




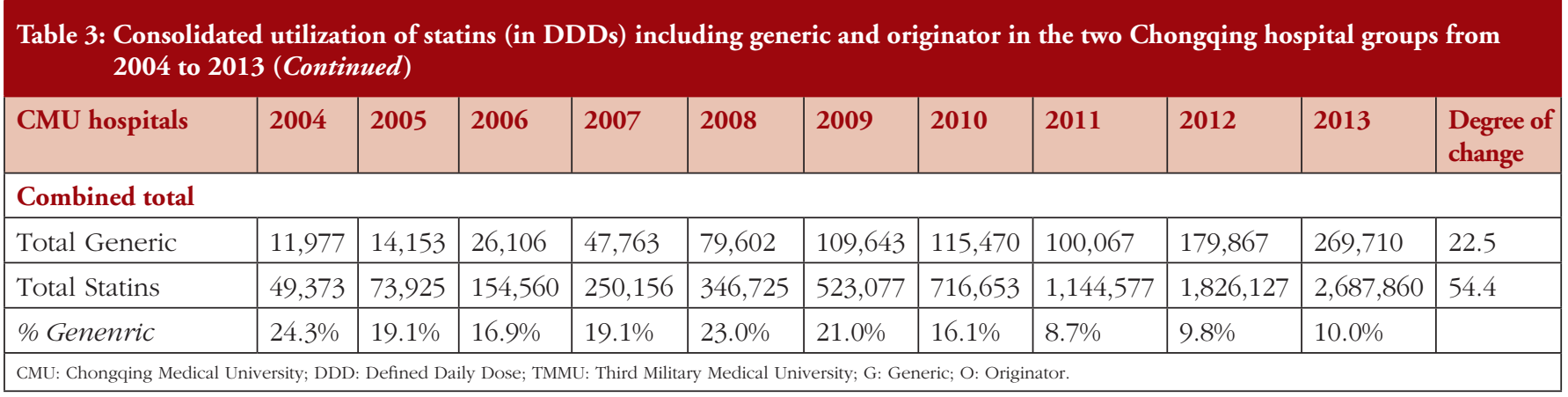

\section{Expenditure}

Total expenditure on the statins increased appreciably in both hospitals, rising from just over CNY 650,000 in 2004 to $\mathrm{CNY}$ 15.3 million in 2013 for the TMMU hospitals, and from CNY 493,000 to CNY 19.3 million for the CMU hospitals, see Figures 3 and 4 . The greatest expenditure was on atorvastatin, amounting to $60-61 \%$ of total statin expenditure in the two hospitals, see Figures 3 and 4 .

In the TMMU hospitals, the lower increase in total expenditure (24-fold) versus utilization (32-fold) was helped by reducing expenditure/DDD for the various statins, see Table 4 . There was a numerically smaller but statistically insignificant ( $p>0.05$ using Fisher exact test) decrease of $23 \%$ for originator statins combined in 2013 vs 2004 compared with a 38\% decrease for generics. This resulted in an overall $27 \%$ price reduction for combined statins between 2004 and 2013, see Table 4 .

In the CMU hospitals, the smaller increase in total expenditure (39-fold) versus utilization (54-fold) was again helped by reducing expenditure/DDD for the various statins, see Table 4. There was a numerically greater decrease for originator statins combined at 34\% in 2013 vs 2004 compared with only 3\% for generics. However, this difference also did not reach statistical significance ( $p>0.05$ using Fisher exact test). These changes resulted, however, in an overall $28 \%$ price reduction for combined statins between 2004 and 2013, see Table 4 .

\section{Figure 3: Total expenditure of statins in CNY in the TMMU} hospitals from 2004 to 2013

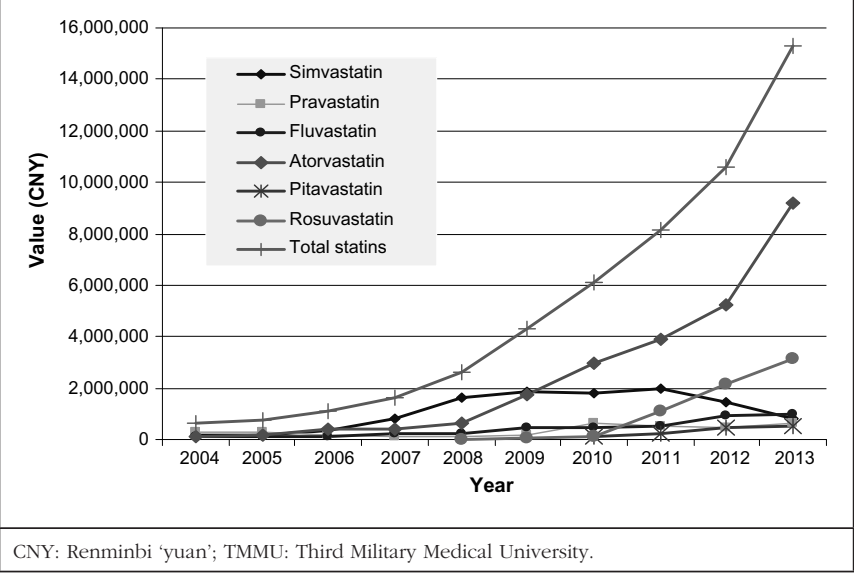

There was considerable variation in price reductions for individual generic and originator statins over the course of the study. The greatest price decline was observed for simvastatin. Prices of the originator declined by $54-56 \%$ in the two hospital groups over the course of the study, with prices for generic simvastatin declining even further, see Table 4.

Whilst the two hospital groups participate in the pharmaceutical tendering process in Chongqing District, the displayed expenditure/ DDD of statins showed differences, see Table 4 . These are mainly attributable to the different specifications during the procurement process between the two hospitals, e.g. $40 \mathrm{mg} \times 7$ 's in TMMU hospital and $40 \mathrm{mg} \times 7$ 's and $20 \mathrm{mg} \times 7$ 's in CMU hospitals for originator simvastatin, $20 \mathrm{mg} \times 7$ 's in TMMU hospital and $10 \mathrm{mg} \times 7$ 's in CMU hospitals for generic atorvastatin in 2013. In addition, some products (e.g. capsules in the TMMU hospitals and tablets in the CMU hospitals for generic simvastatin) with different dosage forms and manufacturers were procured differently by the two hospital groups.

\section{Discussion}

There appears to be progress with obtaining reasonable price reductions for generics versus originators in hospitals in China. This can be seen with procured price reductions over time for generic statins as well as for originators, see Table 4 . However, some prices of the generics appeared initially higher than originators, e.g. pravastatin, pitavastatin and rosuvastatin in the TMMU hospitals and atorvastatin in the CMU hospitals, see Table 4. This could due to a limited price differential policy between the manufacturers of originator and generic drugs

\section{Figure 4: Total expenditure of statins in CNY in the CMU hospitals from 2004 to 2013}

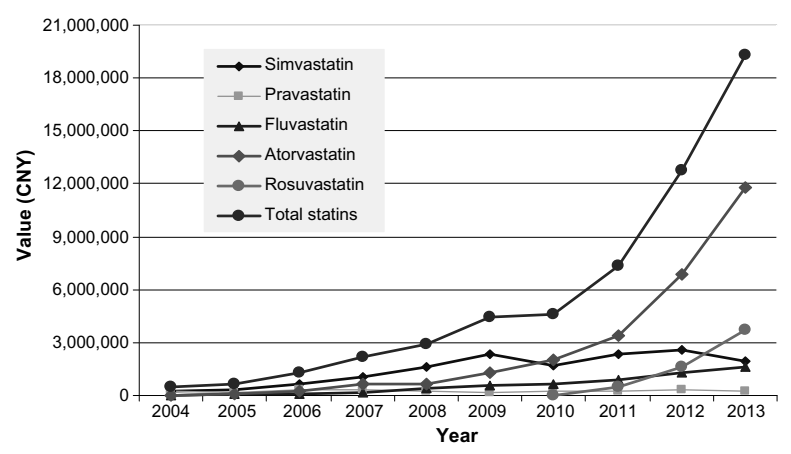

CNY: Renminbi ‘yuan'; CMU: Chongqing Medical University 


\section{Table 4: Expenditure/DDD for statins (generic and originator) in the two Chongqing hospitals from 2004 to 2013}

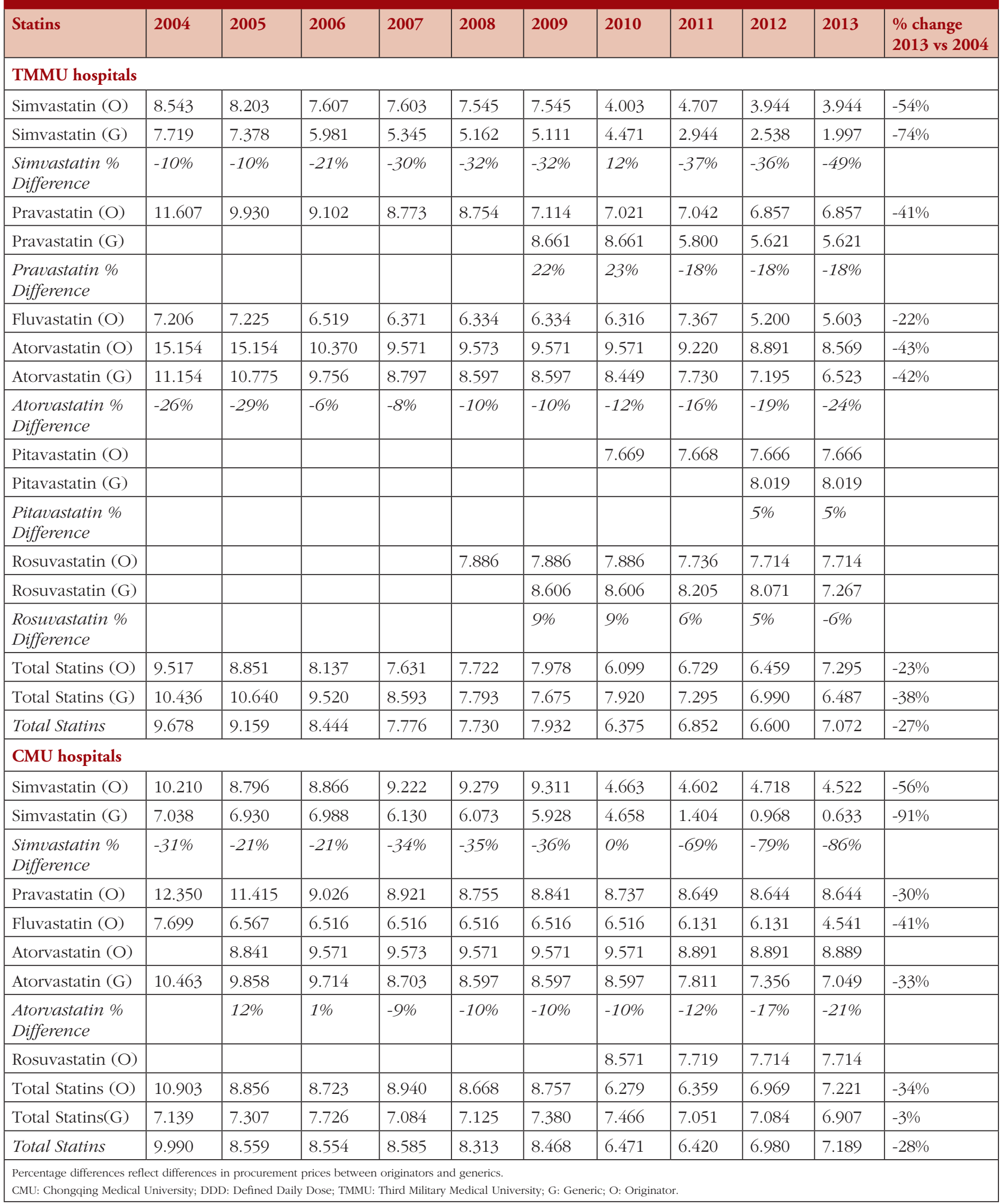


initially. At the first requested procurement opportunity, prices were self-determined by manufacturers and the whole supply chain prefers higher prices with higher profits. Subsequently, the products entered the medicine insurance list and their prices decreased either through government control or greater competition from multiple manufacturers.

The price reductions for generics over time mirror some of those seen in Western European countries [2, 12, 18, 21, 54, 60]. However, there are still opportunities for further price reductions with generic simvastatin, which is priced at between $2 \%$ to $4 \%$ of patented prices in The Netherlands, Sweden and the UK for example [12, 13, 18, 21]. Potential initiatives could include new regulations encouraging greater transparency in the pricing of generics. In the UK, this resulted in the prices of generics falling by $32.4 \%$ in the first year of the introduction and generic simvastatin priced at just $3 \%$ of pre-patent loss prices in recent years $[6,12,25]$.

There continued to be irrationality in the prescribing of statins over time. This included the limited and variable prescribing of generic statins versus originators despite appreciably lower prices, see Tables 3 and 4 . Generics utilization reached a maximum of 27-28\% of total statins between 2012 and 2013 in the TMMU hospital group having fallen to between 12\% and 15\% of total statins between 2008 and 2010, see Table 3. However, utilization decreased from $24 \%$ of total statins in 2004 to $10 \%$ in 2013 in the CMU hospitals, see Table 3. Continued irrationality was also seen by the growing utilization of atorvastatin versus simvastatin, and limited use of generic simvastatin, see Figures 1 and 2, Table 3, with both seen as therapeutically similar at appropriate doses [12, 15, 16-18]. Simvastatin originator (cheapest) was priced between $49 \%$ and $58 \%$ lower than atorvastatin originator (most expensive) between 2010 and 2013 in the TMMU hospitals (47\% to 51\% in the CMU hospitals), and simvastatin generic (cheapest) was between $68 \%$ and $77 \%$ cheaper than originator atorvastatin in the TMMU hospitals in recent years (84\% to 93\% in CMU hospitals), see Table 4.

Overall, there appears to be considerable opportunities to enhance the utilization of low cost generics versus originators, especially following recent reforms in China to improve manufacturing standards for generics. These new standards include strict quality control for generics as part of the tendering process $[35,40]$. A number of quality control measures were introduced after 2000 in China [35]. For instance as of 2009, all medicines on the Chinese Essential Medicines List are required to undergo quality sampling and testing at the provincial level at least annually and at the central level at least every three years to be considered eligible for procurement [35]. Good Manufacturing Practice (GMP) standards were also revised in 2011 to further improve the quality of generics manufacturing in China, adding to the potential trust in generics [35].

However, it is likely future demand-side measures will have only limited success unless the current incentives encouraging physicians and hospitals to prescribe and dispense premium priced originators versus lower cost generics are addressed [29, $31,33,53]$. Once these are adequately addressed, potential additional demand-side measures could include greater enforcement of INN prescribing. Voluntary INN prescribing in Scotland, achieved through a variety of demand-side measures, including physician training in medical schools and follow-up in ambulatory care, resulted in INN prescribing rates of 98\% to $99 \%$ of total utilization among a range of classes and drugs [60].

There are also opportunities to enhance the rational use of medicines in China, building on the essential medicine list concept [33, $35,49]$. This includes encouraging the preferential prescribing of low cost multiple sourced drugs versus more expensive 'singlesourced' [patented] products or originators, and building on INN prescribing. Restricting prescribing choices should enhance physician familiarity with the medicines they prescribe. This could potentially reduce adverse drug reactions and drug: drug interactions as well as strengthen the procurement process. This was the philosophy behind the generation of the 'Wise List' in the Stockholm Healthcare Region, Sweden, which contains approximately 200 drugs including first- and second-line choices covering most of the needs in ambulatory care [21, 24, 65]. An additional 100 drugs are included in a separate list reserved for common needs in specialist inpatient and outpatient care. High adherence rates at $80 \%$ to $90 \%$ to the voluntary 'Wise List' are enhanced by the involvement of prescribers in the selection process, a comprehensive communication programme including a separate list for both patients and physicians, physician trust in the guidance, as well as regular feedback [24, 65]. Increased adherence also reduces costs $[21,24,66]$. There are similar examples in Spain and Scotland $[12,60,65]$.

Such a system could be introduced throughout the hospitals in the Chongqing District along with continuous medical education and strengthening of hospital DTCs. This could provide an example to other provinces and municipalities throughout China as they grapple with similar issues. This will require strong leadership to achieve this, including instigating quality measures and involving prescribers [67] but the potential economic benefits are great. Restricting the formulary to just one statin based on the cheapest statin (simvastatin) would have saved an accumulated CNY 27 million for the TMMU hospitals alone between 2004 and 2013. Accumulated savings could increase to $\mathrm{CNY} 49$ million with the attainment of generics prices similar to low prices achieved in some Western European countries. Simvastatin is recommended in the 'Wise List' in Stockholm County Council [66]. In addition, SIGN (Scottish Intercollegiate Guidelines Network) in Scotland advocate the use of only $40 \mathrm{mg}$ simvastatin for the prevention of cardiovascular disease [68, 69] as well as for primary prevention of cardiovascular disease in patients with Type 1 diabetes. In addition, $40 \mathrm{mg}$ simvastatin or $10 \mathrm{mg}$ atorvastatin are used for the prevention of cardiovascular disease in patients with Type 2 diabetes irrespective of starting lipid levels $[69,70]$. The IDEAL study failed to show a significant reduction in coronary vascular events for patients prescribed high dose atorvastatin ( $80 \mathrm{mg}$ /day) versus low dose simvastatin (20 mg/day) further endorsing the choice of generic simvastatin in such patients [71]. However, we concede that initially it may be better to offer a choice, e.g. simvastatin and atorvastatin, based on current utilization patterns and guidance.

While it remains to be proven, we believe these findings are generalizable to other drug classes and other hospitals in China based on the merits of our methodology as well as the 
realities of current regulations and tendering systems in China. However, this is a recognized weakness of our approach. Nevertheless, we believe our conclusions that ongoing reforms in China are leading to price reductions, mirroring those seen in other countries, are justified. We also feel that there is still an opportunity to achieve further substantial price reductions and that there are also considerable opportunities to enhance the rational use of medicines, achieving further savings without compromising care. We believe these can be achieved through active formulary management and an increase in continuous physician medical education. This includes benchmarking physician prescribing habits similar to what has been achieved by initiatives in Scotland, Spain and Sweden [60, 65]. However, as discussed, for long term, sustained rational use of medicines in China, there must be changes in the remuneration system for hospitals and physicians to reduce their reliance on the profitability from drug procurement for their continued sustainability. This would build on current contracting initiatives in hospitals in other districts and settings [31, 72]. In addition, professionalism must be improved in all aspects of hospital management [73] and perhaps introducing regulations and laws to reduce unethical practices. These could mirror recent regulations and laws in Europe, Korea and the US [6, 19, 74, 75]. When combined, these potential changes should also enhance patient access to essential medicines as well as reduce their co-payments without increasing costs to the Chinese authorities or compromising patient care. As a result, help the Chinese authorities achieve their long term goal of providing universal healthcare access.

In conclusion, we believe we have demonstrated that despite recent measures there is still considerable irrationality in prescribing in China. There are also considerable opportunities to conserve resources without compromising care.

\section{Acknowledgements and conflicts of interest}

We thank the publishing company of the journal China Pharmacy for providing us with the datasets used in this study.

Part of the analysis and writing of this paper was supported by a grant from Karolinska Institutet. There are no additional funding sources.

The authors declare that they have no conflicts of interest apart from those stated. No writing assistance was utilized in the production of this manuscript.

\section{Competing interests: None.}

Provenance and peer review: Not commissioned; externally peer reviewed.

\section{Authors}

Wenjie Zeng ${ }^{1}$, Bsc, PhD

Houmei $\mathrm{Xi}^{1}$, B Eng

Brian Godman ${ }^{2,3,4}, \mathrm{BSc}, \mathrm{PhD}$

AE Finlayson 5 , MD, MRCP

Rickard E Malmstrom ${ }^{6}, \mathrm{MD}, \mathrm{PhD}$

${ }^{1}$ School of Management, Chongqing Jiaotong University, No.66 Xuefu Road, Nan'an District, Chongqing 400074, China
${ }^{2}$ Department of Laboratory Medicine, Division of Clinical Pharmacology, Karolinska Institutet, Karolinska University Hospital Huddinge, SE-14186, Stockholm, Sweden

${ }^{3}$ Strathclyde Institute of Pharmacy and Biomedical Sciences, University of Strathclyde, Glasgow, UK

${ }^{4}$ Liverpool Health Economics Centre, Liverpool University, Chatham Street, Liverpool L69 7ZH, UK

${ }^{5}$ Green Templeton College, University of Oxford, Oxford OX2 $6 \mathrm{HG}, \mathrm{UK}$

${ }^{6}$ Pharmacology Unit, Department of Medicine Solna, Karolinska Institutet, Karolinska University Hospital, SE-17176 Stockholm, Sweden

\section{References}

1. Godman B, Bennie M, Baumgärtel C, et al. Essential to increase the use of generics in Europe to maintain comprehensive healthcare? Farmeconomia: Health Economics and Therapeutic Pathways. 2012;13 Suppl 3:5-20.

2. Godman B, Abuelkhair M, Vitry A, Abdu S, et al. Payers endorse generics to enhance prescribing efficiency; impact and future implications, a case history approach. Generics and Biosimilars Initiative Journal (GaBI Journal). 2012;1(2):69-83. doi:10.5639/gabij.2012.0102.017

3. OECD (2011). Pharmaceutical expenditure, in Health at a Glance 2011: OECD Indicators, OECD Publishing. doi:10.1787/health_glance-2011-63-en. [cited 2014 Mar]. Available from: http://www.oecd.org/els/health-systems/49105858.pdf

4. Godman B, Wettermark B, Bishop I, Burkhardt T, Fürst J, et al. European payer initiatives to reduce prescribing costs through use of generics. Generics and Biosimilars Initiative Journal (GaBI Journal). 2012;1(1):22-7. doi:10.5639/ gabij.2012.0101.007

5. Garattini S, Bertele V, Godman B, et al. Enhancing the rational use of new medicines across European healthcare systems. Eur J Clin Pharmacol. 2008;64(12):1137-8.

6. Godman B, Campbell S, Suh HS, et al. Ongoing measures to enhance prescribing efficiency across Europe: implications for other countries. J Health Tech Assess. 2013;1:27-42.

7. Godman B, Paterson K, Malmström R, et al. Improving the managed entry of new medicines: sharing experiences across Europe. Expert Rev Pharmacoecon Outcomes Res. 2012;12(4):439-41

8. Malmström E, Godman B, Diogene E, et al. Dabigatran - a case history demonstrating the need for comprehensive approaches to optimize the use of new drugs. Front Pharmacol. 2013;4:39. doi:10.3389/fphar.2013.00039

9. Dylst P, Vulto A, Simoens S. Demand-side policies to encourage the use of generic medicines: an overview. Expert Rev Pharmacoecon Outcomes Res. 2013;13(1):59-72.

10. Simoens S. A review of generic medicine pricing in Europe. Generics and Biosimilars Initiative Journal (GaBI Journal). 2012;1(1):8-12. doi:10.5639/ gabij.2012.0101.004

11. Vogler S, Zimmermann N. How do regional sickness funds encourage more rational use of medicines, including the increase of generic uptake? A case study from Austria. Generics and Biosimilars Initiative Journal (GaBI Journal). 2013;2(2):65-75. doi:10.5639/gabij.2013.0202.027

12. Bennie M, Godman B, Bishop I, Campbell S. Multiple initiatives continue to enhance the prescribing efficiency for the proton pump inhibitors and statins in Scotland. Expert Rev Pharmacoecon Outcomes Res. 2012;12(1):125-30.

13. Godman B, Shrank W, Andersen M, et al. Comparing policies to enhance prescribing efficiency in Europe through increasing generic utilization: changes seen and global implications. Expert Rev Pharmacoecon Outcomes Res. 2010; 10(6):707-22.

14. Godman B, Malmstrom RE, Bennie M, et al. Prescribing restrictions - a necessary strategy among some European countries to enhance future prescribing efficiency? Reviews in Health Care. 2012;3(1):5-16. 
15. Sakshaug S, Furu K, Karlstad $\varnothing$, et al. Switching statins in Norway after new reimbursement policy: a nationwide prescription study. Br J Clin Pharmacol. 2007;64(4):476-81.

16. Martikainen J, Saastamoinen LK, Korhonen MJ, et al. Impact of restricted reimbursement on the use of statins in Finland: a register-based study. Med Care. 2010;48(9):761-6.

17. Usher-Smith J, Ramsbottom T, Pearmain H, Kirby M. Evaluation of the clinical outcomes of switching patients from atorvastatin to simvastatin and losartan to candesartan in a primary care setting: 2 years on. Int J Clin Pract. 2008; 62(3):480-4

18. Woerkom Mv, Piepenbrink H, Godman B, et al. Ongoing measures to enhance the efficiency of prescribing of proton pump inhibitors and statins in The Netherlands; influence and future implications. J Comp Eff Res 2012;1(6):527-38.

19. Vončina L, Strizrep T, Godman B, et al. Influence of demand-side measures to enhance renin-angiotensin prescribing efficiency in Europe: implications for the future. Expert Rev Pharmacoecon Outcomes Res. 2011;11(4):469-79.

20. Weng TC, Yang YH, Lin SJ, et al. A systematic review and meta-analysis on the therapeutic equivalence of statins. J Clin Pharm Ther. 2010;35(2) $139-51$.

21. Godman B, Wettermark B, Hoffman M, et al. Multifaceted national and regional drug reforms and initiatives in ambulatory care in Sweden: global relevance. Expert Rev Pharmacoecon Outcomes Res. 2009;9(1):65-83.

22. Godman B, Wettermark B, Miranda J, et al. Influence of multiple initiatives in Sweden to enhance ARB prescribing efficiency following generic losartan; findings and implications for other countries. Int J Clin Pract. 2013;67(9):853-62.

23. Hesse U, Godman B, Petzold M, et al. Impact of delisting ARBs, apart from losartan, on ARB utilisation patterns in Denmark: implications for other countries. App Health Econ Health Policy. 2013;11(6):677-85.

24. Gustafsson LL, Wettermark B, Godman B, et al. The 'wise list'- a comprehensive concept to select, communicate and achieve adherence to recommendations of essential drugs in ambulatory care in Stockholm. Basic Clin Pharmacol Toxicol. 2011;108(4):224-33.

25. McGinn D, Godman B, Lonsdale J, et al. Initiatives to enhance the quality and efficiency of statin and PPI prescribing in the UK: impact and implications Expert Rev Pharmacoecon Outcomes Res. 2010;10(1):73-85.

26. Wettermark B, Pehrsson A, Juhasz-Haverinen $M$, et al. Financial incentives linked to self-assessment of prescribing patterns: a new approach for quality improvement of drug prescribing in primary care. Qual Prim Care. 2009;17(3):179-89

27. Cameron A, Mantel-Teeuwisse AK, Leufkens HG, Laing RO. Switching from originator brand medicines to generic equivalents in selected developing countries: how much could be saved? Value Health. 2012;15(5):664-73.

28. Kaplan WA, Ritz LS, Vitello M, Wirtz VJ. Policies to promote use of generic medicines in low and middle income countries: a review of published literature, 2000-2010. Health Policy. 2012;106(3):211-24.

29. Zeng W. A price and use comparison of generic versus originator cardiovascular medicines: a hospital study in Chongqing, China. BMC Health Serv Res 2013;13(1):390.

30. Lu C, Ross-Degnan D, Stephens P,et al. Changes in use of antidiabetic medications following price regulations in China (1999-2009). JPHSR 2013;4(1):3-11.

31. Han S, Liang H, Su W, Xue Y, Shi L. Can price controls reduce pharmaceutical expenses? A case study of antibacterial expenditures in 12 Chinese hospitals from 1996 to 2005. Int J Health Serv. 2013;43(1):91-103.

32. Godman B, Zeng W, Zhen J, Feng M, Finlayson AE, Campbell S. Initiatives to improve prescribing efficiency in China and their influence; cardio-cerebral vascular medicines as a case history to provide future direction. Basic Clin Pharmacol Toxicol. 2014;115(Suppl 1):33.

33. Daemmrich A, Mohanty A. Healthcare reform in the United States and China: pharmaceutical market implications. J Pharm Policy Pract. 2014;7(1):9.
34. Liu X, Tang S, Yu B, Phuong NK, Yan F, Thien DD, Tolhurst R. Can rural health insurance improve equity in health care utilization? A comparison between China and Vietnam. Int J Equity Health. 2012;11:10.

35. Barber SL, Huang B, Santoso B, et al. The reform of the essential medicines system in China: a comprehensive approach to universal coverage. J Glob Health. 2013;3(1):010303.

36. Li X, Zhang W. The impacts of health insurance on health care utilization among the older people in China. Soc Sci Med. 2013;85:59-65.

37. Meng $\mathrm{Q}, \mathrm{Xu} \mathrm{L}, \mathrm{Zhang} \mathrm{Y}$, et al. Trends in access to health services and financial protection in China between 2003 and 2011: a cross-sectional study. Lancet. 2012;379(9818):805-14.

38. Li L. The challenges of healthcare reforms in China. Public Health. 2011; 25(1):6-8.

39. Ling RE, Liu F, Lu XQ, Wang W. Emerging issues in public health: a perspective on China's healthcare system. Public Health. 2011;125(1):9-14.

40. Sun J. International experiences of promoting generics use and its implications to China. J Evid Based Med. 2013;6(2):74-80

41. National Health and Family Planning Commission of China: China Health Statistics Annuals 2011. [cited 2014 May]. Available from: http://wsb.moh.gov. cn/htmlfiles/zwgkzt/ptjnj/year2011/index2011.html

42. Yu X, Li C, Shi Y, Yu M. Pharmaceutical supply chain in China: current issues and implications for health system reform. Health Policy. 2010;97(1):8-15.

43. Sun Q, Santoro MA, Meng Q, et al. Pharmaceutical policy in China. Health Aff(Millwood). 2008;27(4):1042-50.

44. Tao T, Xu C, Hu M, et al. Analysis of Chinese pharmaceutical price policy from 1997 to 2011. Chin J Health Policy. 2011;4:46-52. Chinese.

45. Vogler S. The impact of pharmaceutical pricing and reimbursement policies on generics uptake: implementation of policy options on generics in 29 European countries-an overview. Generics and Biosimilars Initiative Journal (GaBI Journal). 2012;1(2):93-100. doi:10.5639/gabij.2012.0102.020

46. Chen Y, Schweitzer SO. Issues in drug pricing, reimbursement, and access in China with references to other Asia-Pacific region. Value Health. 2008;11 Suppl 1:S124-9.

47. Yinan H. Radical treatment for healthcare. China Daily. 2010. [cited 2014 May]. Available from: www.chinadaily.com.cn/china/2010-09/16/content_11309825. htm

48. Wagstaff A, Lindelow M. Can insurance increase financial risk? The curious case of health insurance in China. J Health Econ. 2008;27(4):990-1005.

49. Mao W, Tang S, Chen W. Does perverse economic incentive lead to the irrational uses of medicines? Expert Rev Pharmacoecon Outcomes Res. 2013;13(6):693-6.

50. Shi L, Hung LM, Song K, Rane S, Tsai J, Sun X, et al. Chinese primary care physicians and work attitudes. Int J Health Serv. 2013;43(1):167-81.

51. Jingang A. Which future for doctors in China? Lancet. 2013;382(9896):936-7.

52. Liu L, Lu Z, Zhang X. Analysis of rational use of drugs in community health service facilities. Chinese Health Econ. 2009;28(4):45-7. Chinese.

53. Reynolds L, McKee M. Serve the people or close the sale? Profit-driven overuse of injections and infusions in China's market-based healthcare system. Int J Health Plann Manage. 2011;26(4):449-70.

54. Godman B, Burkhardt T, Bucsics A, et al. Impact of recent reforms in Austria on utilization and expenditure of PPIs and lipid lowering drugs: implications for the future. Expert Rev Pharmacoecon Outcomes Res. 2009;9(5):475-84.

55. Teng L, Xin HW, Blix HS, Tsutani K. Review of the use of defined daily dose concept in drug utilisation research in China. Pharmacoepidemiol Drug Saf. 2012;21(10):1118-24.

56. Grimshaw J, Campbell M, Eccles M, et al. Experimental and quasi-experimental designs for evaluating guidelines implementation strategies. Fam Pract. 2000; 17 Suppl 1:S11-6.

57. Chinese Food and Drug Administration [homepage on the Internet]. 2014 [cited 2014 May]. Available from: http://app1.sfda.gov.cn/datasearch/face3/ base.jsp?tableId $=25 \&$ tableName $=$ TABLE2 2 title $=\% \mathrm{E} 5 \% 9 \mathrm{~B} \% \mathrm{BD} \% \mathrm{E} 4 \mathrm{BA} \% \mathrm{~A} 7 \%$ E8\%8D\%AF\%E5\%93\%81\&bcId=124356560303886909015737447882 
58. Sermet C, Andrieu V, Godman B, et al. Ongoing pharmaceutical reforms in France: implications for key stakeholder groups. Appl Health Econ Health Policy. 2010;8(1):7-24.

59. Vogler S, Zimmermann N, Leopold C, de Joncheere K. Pharmaceutical policies in European countries in response to the global financial crisis. South Med Review. 2011;4(2):69-79.

60. Godman B, Bishop I, Finlayson AE, et al. Reforms and initiatives in Scotland in recent years to encourage the prescribing of generic drugs, their influence and implications for other countries. Expert Rev Pharmacoecon Outcomes Res. 2013;13(4):469-82.

61. World Health Organization. Guidelines for ATC classification and DDD assignment. In Oslo: WHO Collaborating Centre for Drug Statistics Methodology [homepage on the Internet]. 2012 Dec 17 [cited 2014 May]. Available from: www.whocc.no

62. World Health Organization. Introduction to drug utilization research. 2003. WHO International Working Group for Drug Statistics Methodology, WHO Collaborating Centre for Drug Statistics Methodology, WHO Collaborating Centre for Drug Utilization Research and Clinical Pharmacological Services. ISBN 924156234 X (NLM classification: WB 330) [homepage on the Internet]. 2003 Sep 3 [cited 2014 May]. Available from: http://www.who.int/medicines/ areas/quality_safety/safety_efficacy/Drug\%20utilization\%20research.pdf

63. Vlahović-Palcevski V, Gantumur M, Radosević N, et al. Coping with changes in Defined Daily Dose in longitudinal drug consumption databases. Pharm World Sci. 2010;32(2):125-9

64. Rønning M, Blix HS, Harbø BT, Strøm H. Different versions of the anatomical therapeutic chemical classification system and the defined daily dose-are drug utilisation data comparable? Eur J Clin Pharmacol. 2000;56(9-10):723-7.

65. Björkhem-Bergman J, Andersén-Karlsson E, Laing R, et al. Interface management of pharmacotherapy. Joint hospital and primary care drug recommendations. Eur J Clin Pharmacol. 2013;69 Suppl 1:73-8.
66. Norman C, Zarrinkoub R, Hasselström J, et al. Potential savings without compromising the quality of care. Int J Clin Pract. 2009;63(9):1320-6.

67. Karadis K, Tomson G, Wettermark B, et al. (2013). The establishment and expansion of an innovative centre for rational pharmacotherapy-determinants and challenges. Int J Health Plann Manage. 2013 Jun 20. doi:10.1002/ hpm.2202. [Epub ahead of print]

68. Scottish Intercollegiate Guidelines Network (SIGN). Heart Disease. 2007, Updated 2012 [homepage on the Internet]. 2013 Jan 29 [cited 2014 Jul]. Available from: http://www.sign.ac.uk/pdf/qrgchd.pdf

69. Bennie M, Godman B, Bishop I, Campbell S. Multiple initiatives continue to enhance the prescribing efficiency for the proton pump inhibitors and statins in Scotland. Expert Rev Pharmacoecon Outcomes Res. 2012;12(1):125-30.

70. Scottish Intercollegiate Guidelines Network (SIGN). Management of diabetes quick reference guide. March 2010 [homepage on the Internet]. 2012 Oct 15 [cited 2014 Jul]. Available from: http://www.sign.ac.uk/pdf/qrg116.pdf

71. Pedersen TR, Faergeman O, Kastelein JJ, Olsson AG, Tikkanen MJ, Holme I, et al. High-dose atorvastatin vs usual-dose simvastatin for secondary prevention after myocardial infarction: the IDEAL study: a randomized controlled trial. JAMA. 2005;294(19):2437-45.

72. Jian W-Y, Lu M, Cui T, Hu M. Evaluating performance of local case-mix system by international comparison: a case study in Beijing, China. Int J Health Plann Manage. 2011;26(4):471-81.

73. Chen J, Xu J, Zhang C, Fu X. Medical professionalism among clinical physicians in two tertiary hospitals, China. Soc Sci Med. 2013;96:290-6.

74. Roehr B. Drug companies will have to report all payments to US doctors from March 2014. BMJ. 2013;346:f826.

75. Yu SY, Yang BM, Kim JH. New anti-rebate legislation in South Korea. Appl Health Econ Health Policy. 2013;11(4):311-8.

DOI: 10.5639/gabij.2014.0303.030

Copyright (c) 2014 Pro Pharma Communications International 